\title{
Voltage Differencing Current Conveyor Based Voltage-Mode and Current-Mode Universal Biquad Filters with Electronic Tuning Facility
}

\author{
Suvajit Roy ${ }^{1}$, Tapas Kumar Paul ${ }^{1}$, Saikat Maiti ${ }^{2}$, Radha Raman Pal ${ }^{1, *}$ \\ ${ }^{1}$ Department of Physics, Vidyasagar University, Midnapore, West Bengal, India \\ ${ }^{2}$ Department of Physical Science, Mundamari Ushananda Vidyapith (HS), West Bengal, India \\ Received 04 December 2020; received in revised form 05 January 2021; accepted 26 January 2021 \\ DOI: https://doi.org/10.46604/ijeti.2021.6821
}

\begin{abstract}
The objective of this study is to present four new universal biquad filters, two voltage-mode multi-input-single-output (MISO), and two current-mode single-input-multi-output (SIMO). The filters employ one voltage differencing current conveyor (VDCC) as an active element and two capacitors along with two resistors as passive elements. All the five filter responses, i.e., high-pass, low-pass, band-pass, band-stop, and all-pass responses, are obtained from the same circuit topology. Moreover, the pole frequency and quality factor are independently tunable. Additionally, they do not require any double/inverted input signals for response realization. Furthermore, they enjoy low active and passive sensitivities. Various regular analyses support the design ideas. The functionality of the presented filters are tested by PSPICE simulations using TSMC $0.18 \mu \mathrm{m}$ technology parameters with $\pm 0.9 \mathrm{~V}$ supply voltage. The circuits are also justified experimentally by creating the VDCC block using commercially available OPA860 ICs. The experimental and simulation results agree well with the theoretically predicted results.
\end{abstract}

Keywords: voltage differencing current conveyor, universal biquad filter, voltage-mode, current-mode, PSPICE

\section{Introduction}

Analog filters are one of the most important parts of the field of electronics. They find wide applications in high-speed communication, instrumentation, sound system, control engineering, and electroacoustics [1]. A filter that offers all the five filter responses, i.e. high-pass (HP), low-pass (LP), band-pass (BP), band-stop (BS), and all-pass (AP), in a single circuit configuration is known as universal filter. Due to several distinct advantages of current-mode active devices, such as high speed, high dynamic range, low power dissipation, high slew rate, better linearity, low cross-talk, etc. [2], analog circuit designs using current-mode active devices have gained increasing interest.

Several universal filters using various current-mode active devices, such as differential voltage current conveyor (DVCC) [1], voltage differencing buffered amplifier (VDBA) [3], extra X current conveyor transconductance amplifier (EXCCTA) [4], current differencing buffered amplifier (CDBA) [5], multiple-output current controlled current conveyor transconductance amplifier (MO-CCCCTA) [6], differential difference current conveyor transconductance amplifier (DDCCTA) [7], four-terminal floating nullor (FTFN) [8], dual X current conveyor differential input transconductance amplifier (DXCCDITA) [9], differential voltage current controlled conveyor transconductance amplifier (DVCCCTA) [10], current controlled differential difference current conveyor transconductance amplifier (CCDDCCTA) [11], operational transconductance amplifier (OTA) [12-13], second generation current conveyor (CCII) [13], fully differential second generation current

* Corresponding author. E-mail address: rrpal@mail.vidyasagar.ac.in 
conveyor (FDCCII) [14], voltage differencing transconductance amplifiers (VDTA) [15], differential difference current conveyor (DDCC) [16], extra X current controlled conveyor (EXCCCII) [17], voltage differencing extra X current conveyor (VD-EXCCII) [18], etc. have already been reported in literature. However, these filters suffer from one or more of the following disadvantages:

- Use two or more active devices [3-5, 12, 14-16].

- Comparatively large supply voltage is needed [4, 6-7, 9-10, 12, 18].

- Use double/inverted input signals [3, 6, 8-9, 13, 17].

- Unsuitable for IC implementation [4-5, 8-9, 13-14, 17-18].

- Pole frequency and quality factor are not independent of each other $[8,11,13]$.

- Pole frequency and quality factor are not electronically tunable [1, 5, 8, 14].

- Dissipate comparatively large power [1, 3-18].

- Use mixed active devices [13].

Presently, the voltage differencing current conveyor (VDCC) has emerged as an alternative analog device incepted by Biolek in 2008 [19]. The advantageous features of VDCC are that it offers electronically tunable transconductance gain, large bandwidth, and high accuracy.

Though several biquad filters employing VDCC as an active device are reported earlier, they are not free from limitations. For example, in [20], three filters employing a single VDCC have been reported, but all these circuits perform only in voltage-mode. Furthermore, the second and third circuits cannot realize all the five types of filter responses. The VDCC based universal biquad filter reported in [21] works only in current-mode. Despite that, the center frequency of that circuit is comparatively low. A universal current-mode Kerwin-Huelsman-Newcomb (KHN) biquad filter has been mentioned in [22], but two VDCCs are necessary for this circuit. A current-mode universal filter has been described in [23]. The circuit also needs two VDCCs. The voltage-mode Tow-Thomas filter reported in [24] requires two VDCCs, two capacitors (2C), and five resistors $(5 R)$. Additionally, the circuit offers only the BP and LP filter responses.

The single VDCC based filter circuit proposed in [25] offers only LP, BP, and HP filter responses. Moreover, the quality factor and center frequency are not independently tunable. In [26], a voltage-mode biquad filter based on VDCC has been reported. However, three active blocks, $8 R$, and $2 C$ are required to realize it. Also, this circuit cannot deliver all the five filter responses. A biquad filter using VDCC has been reported in [27]. The circuit provides only HP, LP and BP filter responses. The VDCC based universal filter reported in [28] offers only voltage outputs. The pole frequency and quality factor are not independently tunable for this configuration. In [29], a ladder filter has been reported. The circuit uses two VDCCs, 4R, and 5C. It offers only HP and LP filter responses. The VDCC based current-mode universal filters reported in [30-32] employ two active building blocks and four passive components. The center frequencies of these circuits are comparatively low. Besides, they offer comparatively large distortions. In [33], another current-mode universal filter has been reported. It also uses two VDCCs. Despite that, a large power supply is needed to realize this circuit. The transconductance-mode universal filter informed in [34] has the limitation that it employs multiple VDCCs and a large number of passive components. Furthermore, it needs a large power supply.

In this paper, four new configurations of the universal biquad filter (two voltage-mode MISO and two current-mode SIMO) using VDCC and four passive components (two resistors and two capacitors) are introduced. The circuits are fit for integrated circuit implementation. They are capable of delivering all basic filter responses without any alternation in the circuit topologies. The pole frequency $\left(\omega_{\mathrm{o}}\right)$ and quality factor $(Q)$ are independently tunable. Also, the value of $\omega_{\mathrm{o}}$ and $Q$ can be adjusted electronically without hampering bandwidth. There are no requirements for double/inverted input signals in the MISO 
configurations. Moreover, all the circuits possess low active and passive sensitivities. It is worth mentioning that the voltage-mode configurations offer three different BP responses (two non-inverting and one inverting). The current-mode configurations also provide two distinct and different BP as well as LP responses (one inverting and one non-inverting for the second topology and all non-inverting for the first topology).

\section{Voltage Differencing Current Conveyor (VDCC)}

VDCC is a six-terminal active device. It is basically the combination of an OTA and a CCII. The block diagram of VDCC is shown in Fig. 1, where $\mathrm{p}$ and $\mathrm{n}$ are high impedance input ports, $\mathrm{z}, \omega_{p}$, and $\omega_{n}$ are high impedance output ports, and $\mathrm{x}$ is the low impedance output port.

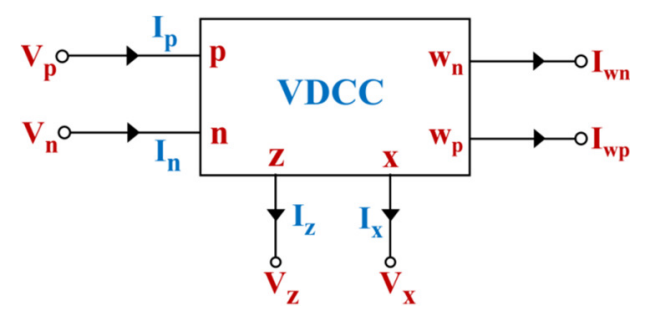

Fig. 1 Block diagram of VDCC

The ideal matrix equation of VDCC is defined as:

$$
\left[\begin{array}{c}
I_{p} \\
I_{n} \\
I_{z} \\
V_{x} \\
I_{w p} \\
I_{w n}
\end{array}\right]=\left[\begin{array}{cccc}
0 & 0 & 0 & 0 \\
0 & 0 & 0 & 0 \\
g_{m} & -g_{m} & 0 & 0 \\
0 & 0 & 1 & 0 \\
0 & 0 & 0 & 1 \\
0 & 0 & 0 & -1
\end{array}\right]\left[\begin{array}{l}
V_{p} \\
V_{n} \\
V_{z} \\
I_{x}
\end{array}\right]
$$

where $\mathrm{g}_{\mathrm{m}}$ is the transconductance gain of the device and can be tuned electronically by changing the bias current $\left(I_{B 1}\right)$. CMOS implementation of VDCC is shown in Fig. 2 [22]. In Fig. 2, the terminals $z_{c}$ and $z_{c-}$ are the two z-copy terminals carrying complementary differential current available at the z-terminal. The currents at those terminals are given by $I_{z_{c}}=I_{z}=-I_{z_{c-}}$.

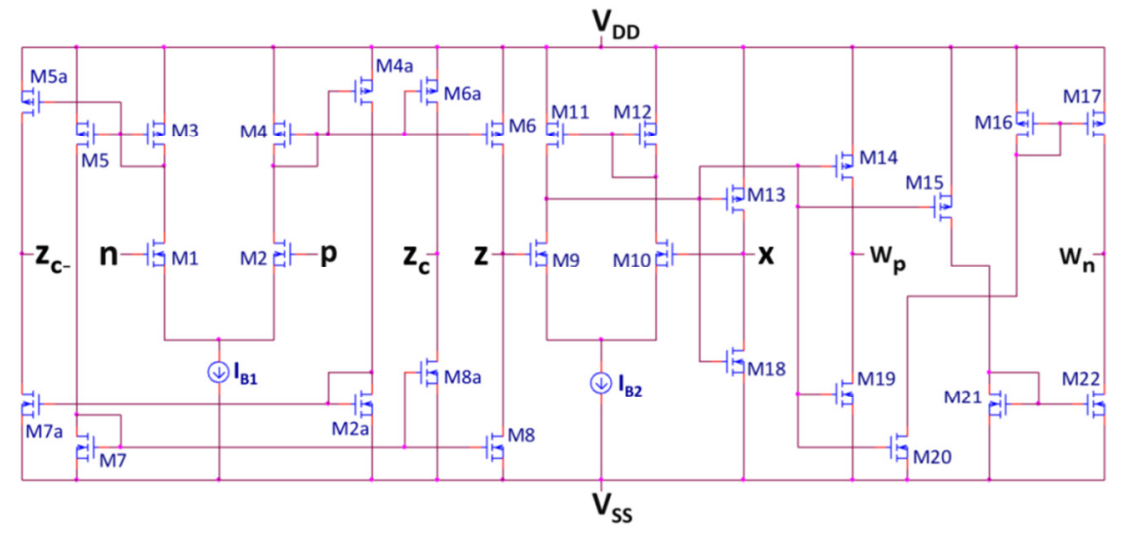

Fig. 2 Internal structure of CMOS VDCC [22]

\section{Proposed Filter Circuits}

\subsection{Voltage-mode filters}

Figs. 3(a) and 3(b) represent the proposed first and second voltage-mode filter circuits respectively. The output voltage $V_{o}$ of these two filters are expressed as: 


$$
V_{o}=\frac{s^{2} C_{1} C_{2} R_{1} R_{2} V_{1}+s C_{2} R_{2} V_{2}-s C_{2} R_{1} V_{3}+s C_{2} R_{1} V_{4}+g_{m} R_{1} V_{5}}{s^{2} C_{1} C_{2} R_{1} R_{2}+s C_{2} R_{2}+g_{m} R_{1}}
$$

Depending on the status of the five voltages in the numerator of Eq. (2), various filter functions can be realized for the circuits of Fig. 3. The filter responses for different status of input voltages are shown in Table 1.

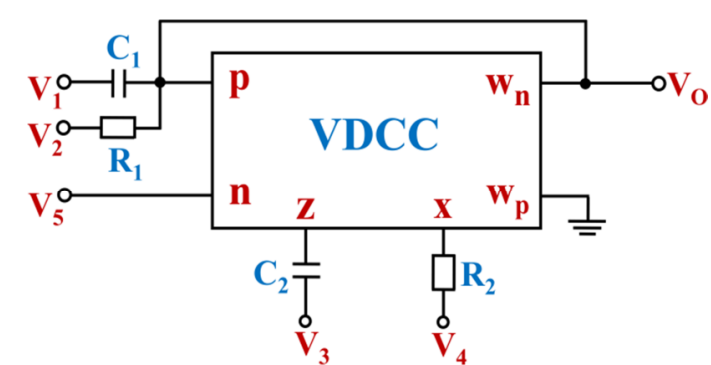

(a) Proposed first topology

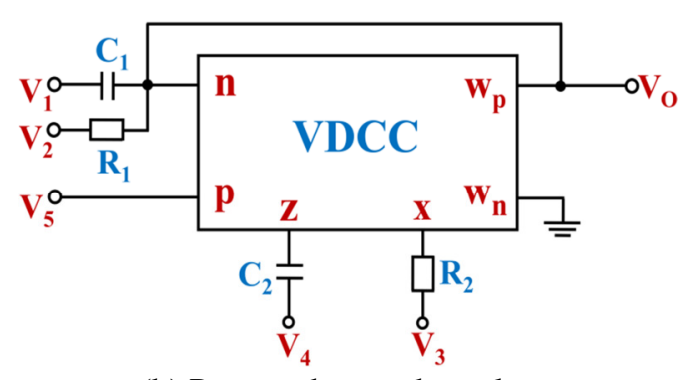

(b) Proposed second topology

Fig. 3 The proposed voltage-mode biquad filters

Table 1 The selection of input voltages for different filter responses of voltage-mode filters

\begin{tabular}{|c|c|c|c|c|c|}
\hline Filter responses & $\mathrm{V}_{1}$ & $\mathrm{~V}_{2}$ & $\mathrm{~V}_{3}$ & $\mathrm{~V}_{4}$ & $\mathrm{~V}_{5}$ \\
\hline $\mathrm{HP}$ & $\mathrm{V}_{\text {in }}$ & 0 & 0 & 0 & 0 \\
\hline $\mathrm{BP} 1$ & 0 & $\mathrm{~V}_{\text {in }}$ & 0 & 0 & 0 \\
\hline $\mathrm{BP} 2$ & 0 & 0 & 0 & $\mathrm{~V}_{\text {in }}$ & 0 \\
\hline $\mathrm{BP} 3$ & 0 & 0 & $\mathrm{~V}_{\text {in }}$ & 0 & 0 \\
\hline $\mathrm{LP}$ & 0 & 0 & 0 & 0 & $\mathrm{~V}_{\text {in }}$ \\
\hline $\mathrm{BS}$ & $\mathrm{V}_{\text {in }}$ & 0 & 0 & 0 & $\mathrm{~V}_{\text {in }}$ \\
\hline $\mathrm{AP}$ & $\mathrm{V}_{\text {in }}$ & 0 & $\mathrm{~V}_{\text {in }}$ & 0 & $\mathrm{~V}_{\text {in }}$ \\
\hline
\end{tabular}

It is worth mentioning here that the proposed voltage-mode configurations offer three different BP responses. BP1 and BP2 give non-inverting outputs, and BP3 gives inverting output.

\subsection{Current-mode filters}

Considering the circuits of Fig. 3 with the following changes as shown in Fig. 4, by grounding all the voltage inputs in Fig. 3 and exciting them with the current input, the routine analysis of the circuits of Fig. 4 yields the various filter transfer functions as depicted in Table 2. The common denominator polynomial $[D(s)]$ in Table 2 is expressed as:

$$
D(s)=s^{2} C_{1} C_{2} R_{1} R_{2}+s C_{2} R_{2}+g_{m} R_{1}
$$

It is worth mentioning here that the proposed current-mode configurations offer two distinct and different BP as well as LP responses. All the responses for the first configuration provide non-inverting outputs, whereas the responses for BP2 and LP1 provide inverting outputs. The gain of the BP2, LP1, and LP2 responses for both the proposed current-mode configurations can be adjusted electronically.

It is noted that, for both of the reported current-mode filters, the currents $I_{1}, I_{2}, I_{3}$, and $I_{4}$ are flowing through grounded passive elements. Thus, additional current followers with virtually grounded inputs will be needed to extract them explicitly. Due to this, the corresponding passive elements will not be physically grounded, but still will be grounded virtually [15].

The filter parameters-pole frequency $\left(\omega_{o}\right)$, quality factor $(Q)$, and bandwidth $(B W)$ for all the proposed voltage and current mode biquad filters are obtained as:

$$
\omega_{o}=\sqrt{\frac{g_{m}}{C_{1} C_{2} R_{2}}}, Q=R_{1} \sqrt{\frac{g_{m} C_{1}}{C_{2} R_{2}}}, B W=\frac{1}{C_{1} R_{1}}
$$




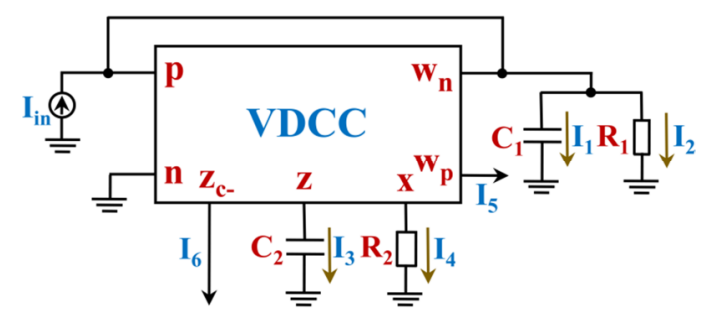

(a) Proposed first topology

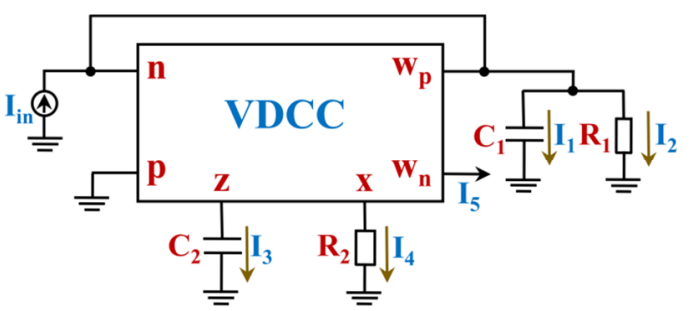

(b) Proposed second topology

Fig. 4 The proposed current-mode biquad filters

Eq. (4) reveals that the value of $Q$ and $\omega_{o}$ can be adjusted electronically by means of $g_{m}$ without hampering the value of $B W$. Eq. (4) also reveals that the value of $Q$ and $\omega_{o}$ can be tuned independently without affecting each other as the value of $Q$ can be controlled with the help of $R_{l}$ without disturbing $\omega_{o}$. Since the $Q$ value is tuned by using passive resistance $\left(R_{l}\right)$ rather than using active resistance restricted in its operating range, a high value of $Q$, which is a desirable property for any filter circuit, can be achieved for the proposed structures. The value of $\omega_{o}$ can be adjusted for a particular $Q$ value by selecting the following arrangements:

$$
g_{m} R_{1}=1 \text { and } R_{1}=R_{2}
$$

Table 2 The transfer function for different filter responses of the proposed current-mode filters

\begin{tabular}{|c|c|c|}
\hline Filter responses & Fig. 4(a) & Fig. 4(b) \\
\hline HP & $\frac{I_{1}}{I_{\text {in }}}=\frac{s^{2} C_{1} C_{2} R_{1} R_{2}}{D(s)}$ & $\frac{I_{1}}{I_{\text {in }}}=\frac{s^{2} C_{1} C_{2} R_{1} R_{2}}{D(s)}$ \\
\hline BP1 & $\frac{I_{2}}{I_{\text {in }}}=\frac{s C_{2} R_{1}}{D(s)}$ & $\frac{I_{2}}{I_{\text {in }}}=\frac{s C_{2} R_{2}}{D(s)}$ \\
\hline BP2 & $\frac{I_{3}}{I_{\text {in }}}=\frac{s C_{2} R_{1} R_{2} g_{m}}{D(s)}$ & $\frac{I_{3}}{I_{\text {in }}}=\frac{s C_{2} R_{1} R_{2} g_{m}}{D(s)}$ \\
\hline LP1 & $\frac{I_{4}}{I_{i n}}=\frac{R_{1} g_{m}}{D(s)}$ & $\frac{I_{4}}{I_{\text {in }}}=\frac{R_{1} g_{m}}{D(s)}$ \\
\hline LP2 & $\frac{I_{5}}{I_{\text {in }}}=\frac{R_{1} g_{m}}{D(s)}$ & $\frac{I_{5}}{I_{\text {in }}}=\frac{R_{1} g_{m}}{D(s)}$ \\
\hline BS & $\frac{I_{1}+I_{4}}{I_{\text {in }}}=\frac{s^{2} C_{1} C_{2} R_{1} R_{2}+R_{1} g_{m}}{D(s)}$ & $\frac{I_{1}+I_{5}}{I_{\text {in }}}=\frac{s^{2} C_{1} C_{2} R_{1} R_{2}+R_{1} g_{m}}{D(s)}$ \\
\hline $\begin{array}{c}\mathrm{AP} \\
\text { (If } R_{1} g_{m}=1 \text { ) }\end{array}$ & $\frac{I_{1}+I_{5}+I_{6}}{I_{\text {in }}}=\frac{s^{2} C_{1} C_{2} R_{1} R_{2}-s C_{2} R_{2}+R_{1} g_{m}}{D(s)}$ & $\frac{I_{1}+I_{3}+I_{5}}{I_{\text {in }}}=\frac{s^{2} C_{1} C_{2} R_{1} R_{2}-s C_{2} R_{2}+R_{1} g_{m}}{D(s)}$ \\
\hline
\end{tabular}

\section{Non-Ideal and Sensitivity Analysis}

The non-ideal characterizing equation of the VDCC block is expressed as:

$$
\left[\begin{array}{c}
I_{p} \\
I_{n} \\
I_{z} \\
V_{x} \\
I_{w p} \\
I_{w n}
\end{array}\right]=\left[\begin{array}{cccc}
0 & 0 & 0 & 0 \\
0 & 0 & 0 & 0 \\
\alpha g_{m} & -\alpha g_{m} & 0 & 0 \\
0 & 0 & \beta & 0 \\
0 & 0 & 0 & \gamma_{p} \\
0 & 0 & 0 & -\gamma_{n}
\end{array}\right]\left[\begin{array}{l}
V_{p} \\
V_{n} \\
V_{z} \\
I_{x}
\end{array}\right]
$$

where $\alpha, \gamma_{p}$, and $\gamma_{n}$ are the current tracking errors, and $\beta$ is the voltage tracking error of the VDCC. By reanalyzing the circuits for the above non-ideal values, the expression of the common denominator polynomial for all the proposed filters becomes:

$$
D(s)^{\prime}=s^{2} C_{1} C_{2} R_{1} R_{2}+s C_{2} R_{2}+\alpha \beta \gamma_{i} g_{m} R_{1}
$$

where $\gamma_{i}=\gamma_{n}$ for the circuits of Figs. 3(a) and 4(a), and $\gamma_{i}=\gamma_{p}$ for the circuits of Figs. 3(b) and 4(b). 
From Eq. (7), the pole frequency, quality factor, and bandwidth of the reported circuits are found as:

$$
\omega_{o}^{\prime}=\sqrt{\frac{\alpha \beta \gamma_{i} g_{m}}{C_{1} C_{2} R_{2}}}, Q^{\prime}=R_{1} \sqrt{\frac{\alpha \beta \gamma_{i} g_{m} C_{1}}{C_{2} R_{2}}}, B W^{\prime}=B W=\frac{1}{C_{1} R_{1}}
$$

Eq. (8) shows that though the bandwidth of the circuits remains unaltered due to the non-ideality errors of the VDCC, the pole frequency and quality factor are slightly changed. However, the pole frequency and quality factor are still electronically tunable. Also, they are still independently controllable under the same conditions mentioned earlier.

The active and passive sensitivities of the parameters pole frequency, quality factor, and bandwidth for the proposed filters are given as:

$$
\begin{aligned}
& s_{\alpha, \beta, \gamma_{n}, g_{m}}^{\omega_{0}^{\prime}}=-s_{C_{1}, C_{2}, R_{2}}^{\omega_{0}^{\prime}}=\frac{1}{2} \text { and } s_{\gamma_{i}, R_{1}}^{\omega_{0}^{\prime}}=0 \\
& s_{\alpha, \beta, \gamma_{n}, g_{m} C_{1}}^{Q^{\prime}}=-s_{C_{2}, R_{2}}^{Q^{\prime}}=\frac{1}{2} ; s_{\gamma_{i}}^{Q^{\prime}}=0 \text { and } s_{R_{1}}^{Q^{\prime}}=1 \\
& s_{C_{1}, R_{1}}^{B W}=-1 \text { and } s_{\alpha, \beta, \gamma_{p}, \gamma_{n}, g_{m}, C_{2}, R_{2}}^{\omega_{0}}=0
\end{aligned}
$$

Eqs. (9) to (11) confirm that all the active and passive sensitivities do not exceed unity in magnitude. Therefore, the designed circuits indicate a satisfactory sensitivity performance.

\section{Influence of Parasitics}

A usual parasitic model of VDCC [2] is illustrated in Fig. 5. It displays the practical VDCC with a small series parasitic resistance $R_{x}$ at $X$ terminal, the parasitic resistance $R_{p}$ (high) in parallel with parasitic capacitance $C_{p}\left(\right.$ low) at $W_{p}$ terminal, the grounded parasitic resistance $\mathrm{R}_{\mathrm{z}}$ (high) at $\mathrm{Z}$ terminal, and the parasitic resistance $\mathrm{R}_{\mathrm{n}}$ (high) in parallel with parasitic capacitance $\mathrm{C}_{\mathrm{n}}$ (low) at $\mathrm{W}_{\mathrm{n}}$ terminal.

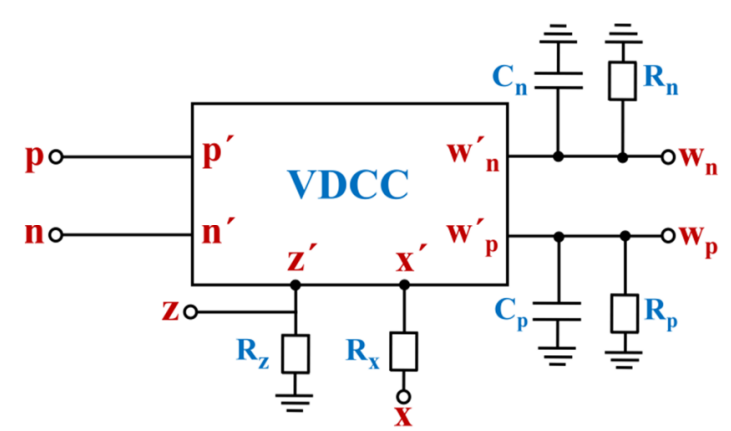

Fig. 5 Parasitic model of VDCC [2]

By reanalyzing the circuits and considering the parasitics of the VDCC, the modified transfer functions of the reported filters are given in Table 3.

The expression of the modified common denominator polynomial $\left[D(s)^{\prime \prime}\right]$ in Table 3 is given by:

$$
\begin{aligned}
& D(s)^{\prime \prime}=s^{2} C_{e} C_{2} R_{e} R_{2 x}+s C_{2} R_{2 x}+s C_{e} \frac{R_{e} R_{2 x}}{R_{z}}+g_{m} R_{e}+\frac{R_{2 x}}{R_{z}} \\
& R_{2 x}=R_{2}+R_{x}, R_{e}=R_{1} \| R_{i} \text { and } C_{e}=C_{1}+C_{i}
\end{aligned}
$$

where $i$ represents $n$ for Figs. 3(a) and 4(a), and represents p for Figs. 3(b) and 4(b). 
Table 3 The transfer function of the reported filters under the parasitics of VDCC

\begin{tabular}{|c|c|c|c|c|}
\hline $\begin{array}{l}\text { Filter } \\
\text { responses }\end{array}$ & Fig. 3(a) & Fig. 3(b) & Fig. 4(a) & Fig. 4(b) \\
\hline \multirow{2}{*}{ HP } & $V_{o} \quad s^{2} C_{1} C_{2} R_{e} R_{2 x}+s C_{1} \frac{R_{e} R_{2 x}}{R_{z}}$ & $V_{o} \quad s^{2} C_{1} C_{2} R_{e} R_{2 x}+s C_{1} \frac{R_{e} R_{2 x}}{R_{Z}}$ & $I_{1} \quad s^{2} C_{e} C_{2} R_{e} R_{2 x}+s C_{e} \frac{R_{e} R_{2 x}}{R_{z}}$ & $I_{1} \quad s^{2} C_{e} C_{2} R_{e} R_{2 x}+s C_{e} \frac{R_{e} R_{2 x}}{R_{z}}$ \\
\hline & $\overline{V_{1}}=\frac{D(s)^{\prime \prime}}{}$ & $\overline{V_{1}}=\frac{D(s)^{\prime \prime}}{}$ & $\overline{I_{\text {in }}}=\frac{D(s)^{\prime \prime}}{}$ & $\overline{I_{\text {in }}}=\frac{D(s)^{n}}{}$ \\
\hline BP1 & $\frac{V_{o}}{V_{2}}=\frac{\frac{R_{e} R_{2 x}}{R_{1}}\left(s C_{2}+\frac{1}{R_{z}}\right)}{D(s)^{\prime \prime}}$ & $\frac{V_{o}}{V_{2}}=\frac{\frac{R_{e} R_{2 x}}{R_{1}}\left(s C_{2}+\frac{1}{R_{z}}\right)}{D(s)^{\prime \prime}}$ & $\frac{I_{2}}{I_{\text {in }}}=\frac{s C_{2} R_{2 x}+\frac{R_{2 x}}{R_{z}}}{D(s)^{\prime}}$ & $\frac{I_{2}}{I_{\text {in }}}=\frac{s C_{2} R_{2 x}+\frac{R_{2 x}}{R_{z}}}{D(s)^{\prime \prime}}$ \\
\hline $\mathrm{BP} 2$ & $\frac{V_{o}}{V_{4}}=\frac{\left(s C_{2} R_{e}+\frac{R_{e}}{R_{z}}\right)}{D(s)^{\prime}}$ & $\frac{V_{o}}{V_{4}}=\frac{s C_{2} R_{e}}{D(s)^{\prime \prime}}$ & $\frac{I_{3}}{I_{\text {in }}}=g_{m} \frac{\left(s C_{2}+\frac{1}{R_{z}}\right)}{D(s)^{\prime \prime}} R_{e} R_{2 x}$ & $\frac{I_{3}}{I_{\text {in }}}=g_{m} \frac{\left(s C_{2}+\frac{1}{R_{z}}\right)}{D(s)^{\prime \prime}} R_{e} R_{2 x}$ \\
\hline BP3 & $\frac{V_{o}}{V_{3}}=\frac{s C_{2} R_{e}}{D(s)^{\prime \prime}}$ & $\frac{V_{o}}{V_{3}}=-\frac{\left(s C_{2} R_{e}+\frac{R_{e}}{R_{Z}}\right)}{D(s)^{\prime}}$ & cho 2 & … \\
\hline LP1 & $\frac{V_{o}}{V_{3}}=\frac{g_{m} R_{e}}{D(s)^{\prime \prime}}$ & $\frac{V_{o}}{V_{3}}=\frac{g_{m} R_{e}}{D(s)^{\prime \prime}}$ & $\frac{I_{4}}{I_{\text {in }}}=\frac{g_{m} R_{e}}{D(s)^{\prime \prime}}$ & $\frac{I_{4}}{I_{\text {in }}}=\frac{g_{m} R_{e}}{D(s)^{\prime \prime}}$ \\
\hline LP2 & 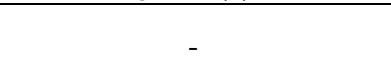 & 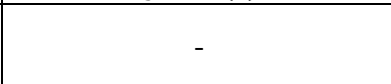 & $\frac{I_{5}}{I_{\text {in }}}=\frac{g_{m} R_{e}}{D(s)^{\prime \prime}}$ & $\frac{I_{5}}{I_{\text {in }}}=\frac{g_{m} R_{e}}{D(s)^{\prime \prime}}$ \\
\hline BS & $\frac{V_{B S}}{V_{\text {in }}}=\frac{V_{o}}{V_{1}}=\frac{V_{o}}{V_{5}}$ & $\frac{V_{B S}}{V_{\text {in }}}=\frac{V_{o}}{V_{1}}=\frac{V_{o}}{V_{5}}$ & $\frac{I_{B S}}{I_{\text {in }}}=\frac{I_{o}}{I_{1}}=\frac{I_{4}}{I_{\text {in }}}$ & $\frac{I_{B S}}{I_{\text {in }}}=\frac{I_{1}}{I_{\text {in }}}=\frac{I_{5}}{I_{\text {in }}}$ \\
\hline $\begin{array}{c}\mathrm{AP} \\
\left(R_{1} g_{m}=1\right)\end{array}$ & $\frac{V_{B S}}{V_{\text {in }}}=\frac{V_{o}}{V_{1}}=\frac{V_{o}}{V_{3}}=\frac{V_{o}}{V_{5}}$ & $\frac{V_{B S}}{V_{\text {in }}}=\frac{V_{o}}{V_{1}}=\frac{V_{o}}{V_{3}}=\frac{V_{o}}{V_{5}}$ & $\frac{I_{A P}}{I_{\text {in }}}=\frac{I_{1}}{I_{\text {in }}}=\frac{I_{5}}{I_{\text {in }}}=\frac{I_{6}}{I_{\text {in }}}$ & $\frac{I_{A P}}{I_{\text {in }}}=\frac{I_{1}}{I_{\text {in }}}=\frac{I_{3}}{I_{\text {in }}}=\frac{I_{5}}{I_{\text {in }}}$ \\
\hline
\end{tabular}

From Eq. (12), the modified pole frequency $\left(\omega_{o}^{\prime \prime}\right)$, quality factor $\left(Q^{\prime \prime}\right)$, and bandwidth $\left(B W^{\prime \prime}\right)$ for the designed filters are obtained as:

$$
\omega_{o}^{\prime \prime}=\sqrt{\frac{g_{m}+\frac{R_{2 x}}{R_{e} R_{z}}}{C_{e} C_{2} R_{2 x}}}, Q^{\prime \prime}=\frac{R_{e}}{C_{2}+C_{e} \frac{R_{e}}{R_{z e}}} \sqrt{C_{e} C_{2}\left(\frac{g_{m}}{R_{2 x}}+\frac{1}{R_{z} R_{e}}\right)}, \mathrm{BW}^{\prime \prime}=\frac{1}{C_{e} R_{e}}+\frac{1}{C_{2} R_{z}}
$$

Though the filter parameters are affected because of the inclusion of VDCC parasitics, it is not obsessive as $R_{z}, R_{p}, R_{n}$ are very high, and $R_{x}, C_{p}, C_{n}$ are very low. Still, the pole frequency and quality factor can be tuned electronically by means of $g_{m}$ without disturbing the bandwidth.

\section{Simulation Results}

The proposed filters are simulated through PSPICE program using TSMC CMOS $0.18 \mu \mathrm{m}$ process parameters (level 7). The VDCC in Fig. 2 has been used for this purpose. The biasing currents are taken as $\mathrm{I}_{\mathrm{B} 1}=50 \mu \mathrm{A}$ and $\mathrm{I}_{\mathrm{B} 2}=100 \mu \mathrm{A}\left(\mathrm{g}_{\mathrm{m}}=277.8\right.$ $\mu \mathrm{A} / \mathrm{V}$ ); supply voltages are chosen as $\mathrm{V}_{\mathrm{DD}}=-\mathrm{V}_{\mathrm{SS}}=0.9 \mathrm{~V}$. The aspect ratios of MOS transistors have been taken same as in [22]. The passive components are selected as $\mathrm{R}_{1}=\mathrm{R}_{2}=3.6 \mathrm{k} \Omega$, and $\mathrm{C}_{1}=\mathrm{C}_{2}=4.7 \mathrm{pF}$. The frequency responses for $\mathrm{HP}, \mathrm{LP}, \mathrm{BP}$, and BS functions of proposed filters are shown in Fig. 6. The pole frequencies are found to be $8.91 \mathrm{MHz}$ for the circuits of Figs. 3(a) and 4(a). The same for the circuits of Figs. 3(b) and 4(b) are found to be $9.12 \mathrm{MHz}$. These are close to the theoretically predicted values (percentage errors are just 5.32\% and 3.1\%, respectively). The gain and phase responses of AP function for the reported filters are demonstrated in Fig. 7. The power dissipation is less than $0.72 \mathrm{~mW}$ for all the proposed circuits.

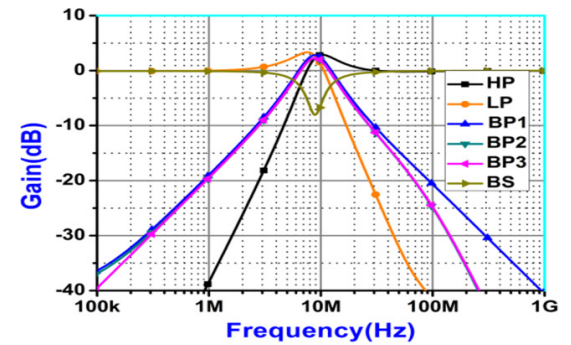

(a) For the circuit of Fig. 3(a)

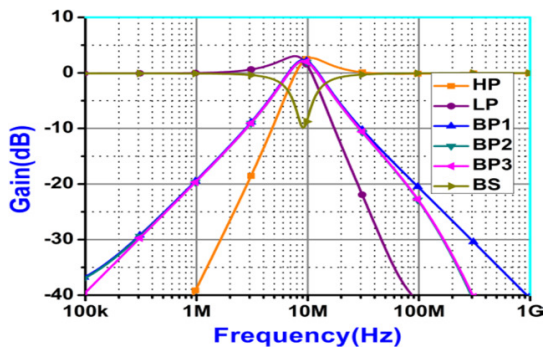

(b) For the circuit of Fig. 3(b)

Fig. 6 The simulated results of the gain-frequency response 


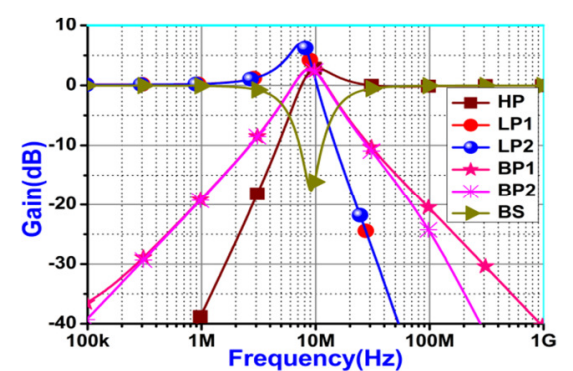

(c) For the circuit of Fig. 4(a)

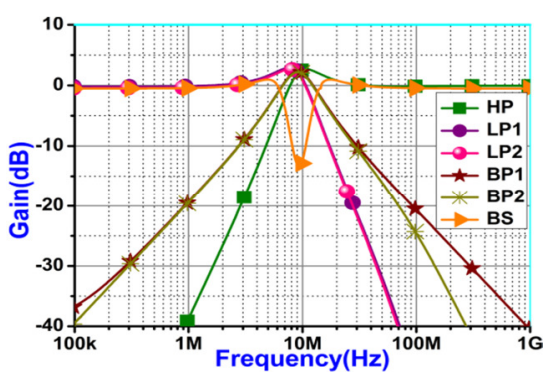

(d) For the circuit of Fig. 4(b)

Fig. 6 The simulated results of the gain-frequency response (continued)

Figs. 6 and 7 depict that the reported circuits enjoy all the standard filter functions very well. The results of BP filter outputs are taken to justify the mutual independence of pole frequency and quality factor. The variations of the quality factor with fixed pole frequency are shown in Fig. 8. To set the value of $\mathrm{Q}$ as 1, 2, 3, and 4, the resistance $\mathrm{R}_{1}$ is chosen as $3.6 \mathrm{k} \Omega, 7.22$ $\mathrm{k} \Omega, 10.8 \mathrm{k} \Omega$, and $14.4 \mathrm{k} \Omega$ respectively.

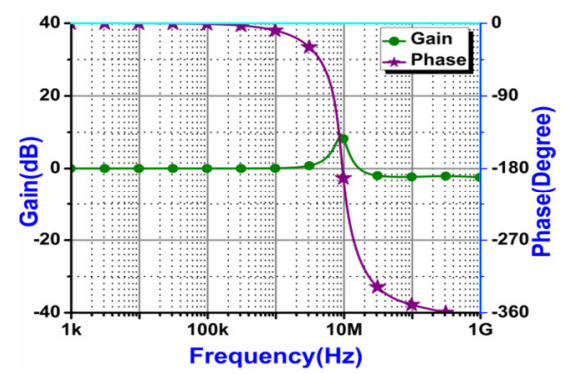

(a) For the circuit of Fig. 3(a)

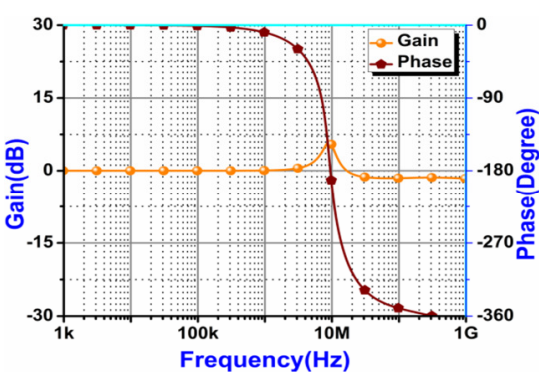

(c) For the circuit of Fig. 4(a)

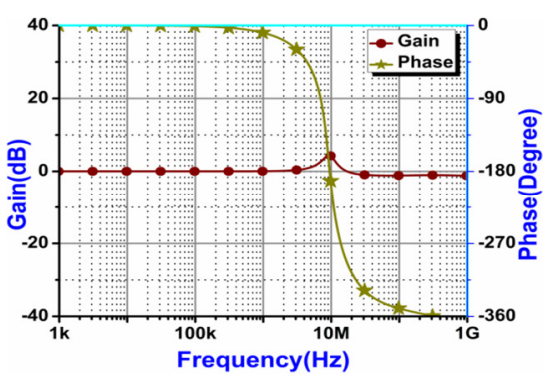

(b) For the circuit of Fig. 3(b)

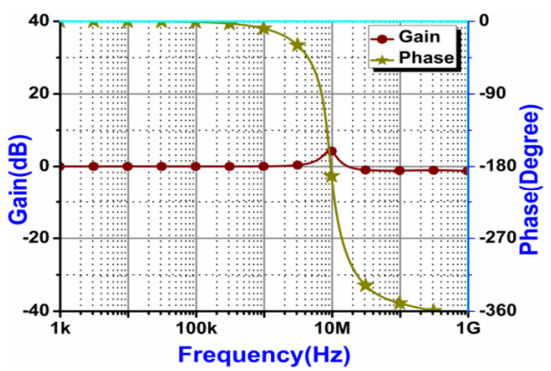

(d) For the circuit of Fig. 4(b)

Fig. 7 The gain and phase-frequency responses of AP function

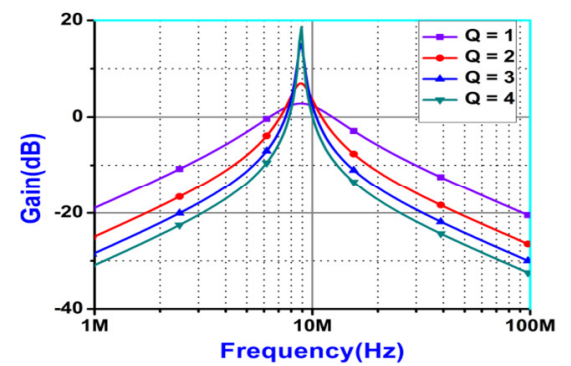

(a) For the circuit of Fig. 3(a)

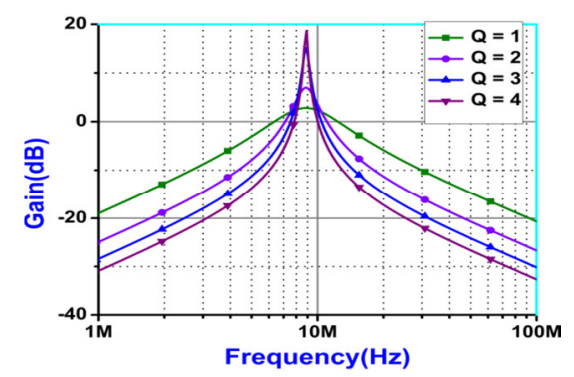

(c) For the circuit of Fig. 4(a)

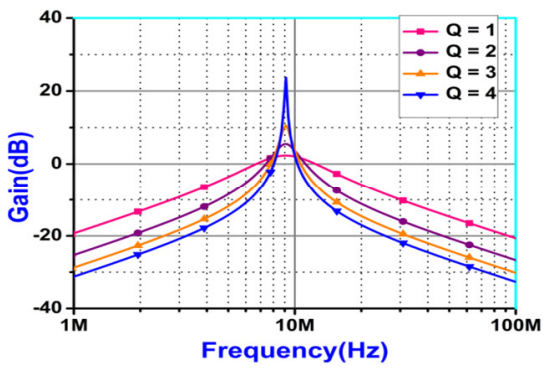

(b) For the circuit of Fig. 3(b)

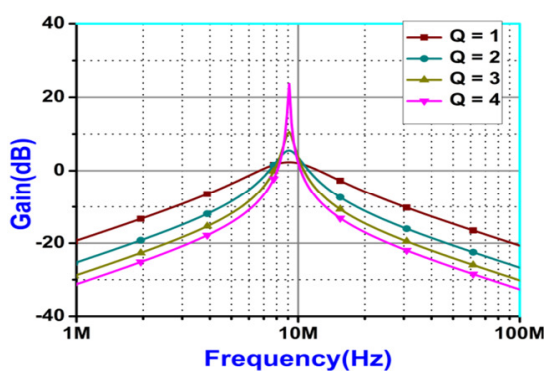

(d) For the circuit of Fig. 4(b)

Fig. 8 The variation of quality factor for a fixed pole frequency 
Similarly, the orthogonal adjustment of $\mathrm{f}_{\mathrm{o}}$ with fixed $Q$ value is depicted in Fig. 9. To obtain these graphs, the value of resistances $R_{1}$ is taken the same as $R_{2}$ and selected as $5.3 \mathrm{k} \Omega, 3.6 \mathrm{k} \Omega, 2.88 \mathrm{k} \Omega$, and $2.3 \mathrm{k} \Omega$. The bias currents are adjusted to keep $g_{m} R_{1}=1$ for each case.

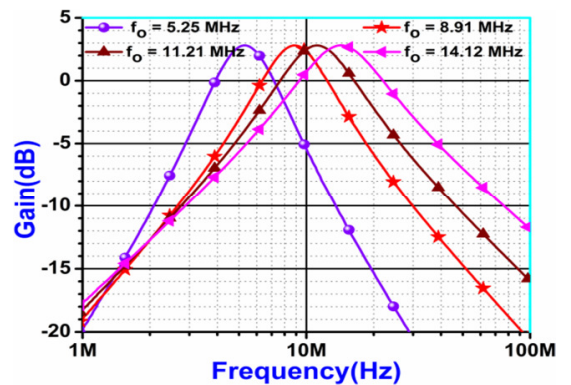

(a) For the circuit of Fig. 3(a)

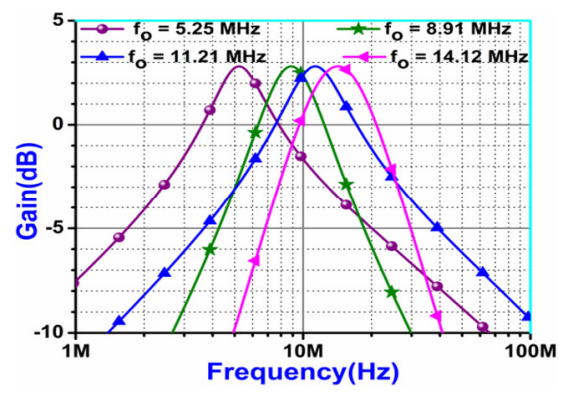

(c) For the circuit of Fig. 4(a)

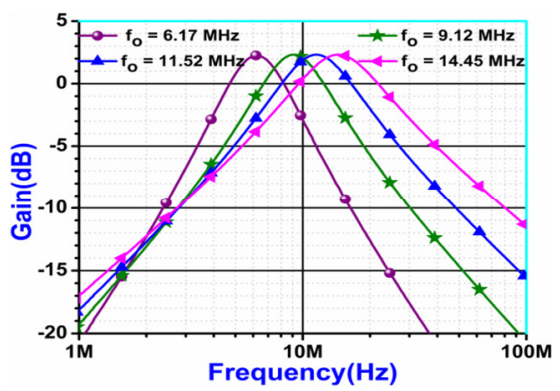

(b) For the circuit of Fig. 3(b)

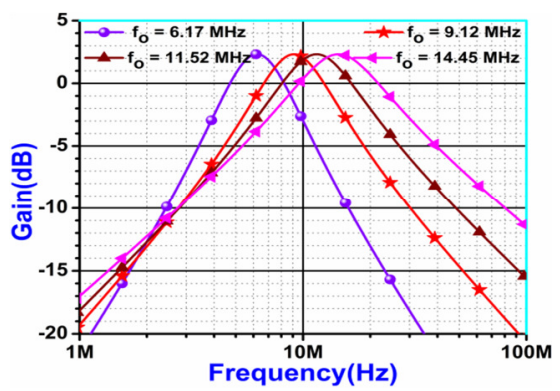

(d) For the circuit of Fig. 4(b)

Fig. 9 The variation of pole frequency for a fixed quality factor

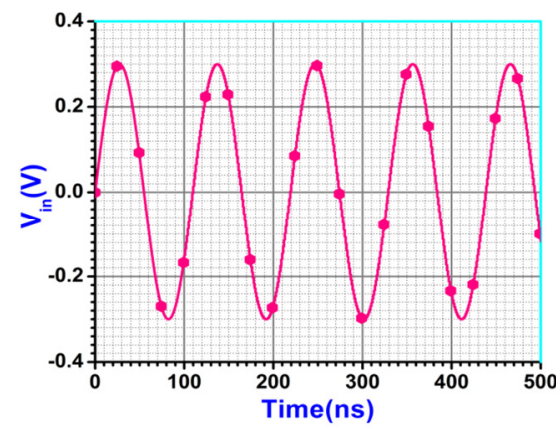

(a) input

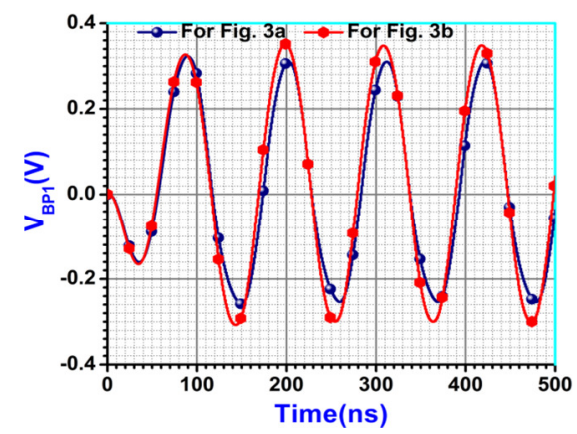

(b) output

Fig. 10 Time domain responses of proposed voltage-mode BP filters

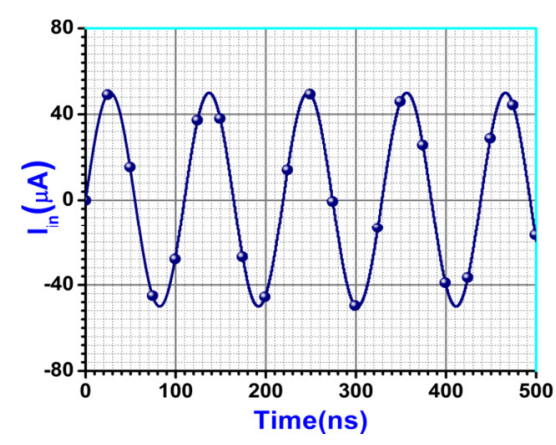

(a) input

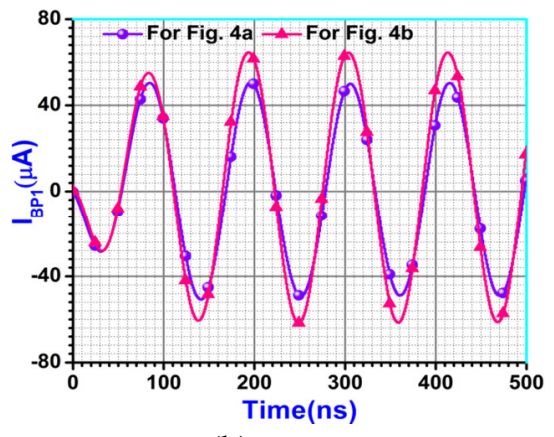

(b) output

Fig. 11 Time domain responses of proposed current-mode BP filters

In addition, to test the dynamic range of the reported filters, a sinusoidal voltage signal of frequency $9.12 \mathrm{MHz}$ and amplitude $300 \mathrm{mV}_{\mathrm{p}}$ is applied as input $\left(\mathrm{V}_{3}\right)$ of the reported voltage-mode filters, whereas a sinusoidal current signal of frequency $9.12 \mathrm{MHz}$ and amplitude $50 \mu \mathrm{A}_{\mathrm{p}}$ is applied as an input of the reported current-mode filters. The simulated input and output waveforms in the time domain for the voltage-mode BP responses are illustrated in Fig. 10, whereas those for the current-mode BP responses are shown in Fig. 11. It is found that the input and output signals are almost equal in magnitude. 
Fig. 12 depicts the variation of total harmonic distortion (THD) against the variation in amplitude of sinusoidal inputs of the proposed filters. The input voltage is varied up to $400 \mathrm{mV}$ for the circuits of Figs. 3(a) and 4(a), whereas the input current is varied up to $200 \mu \mathrm{A}$ for the circuits of Figs. 4(a) and 4(b). The THD is found to be less than 2.4\%, 2.22\%, 2.37\%, 2.27\%, and $2.48 \%$ for all the HP, LP, BP, BS, and AP responses, respectively.

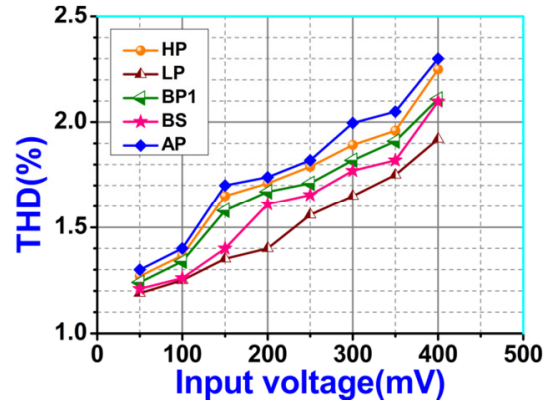

(a) For Fig. 3(a)

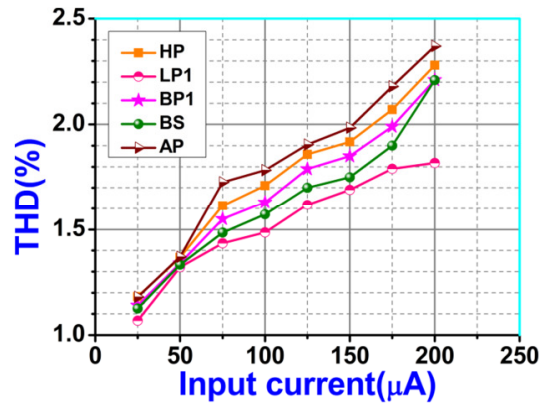

(c) For Fig. 4(a)

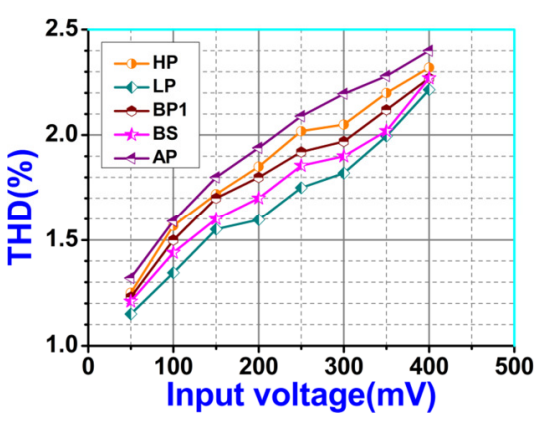

(b) For Fig. 3(b)

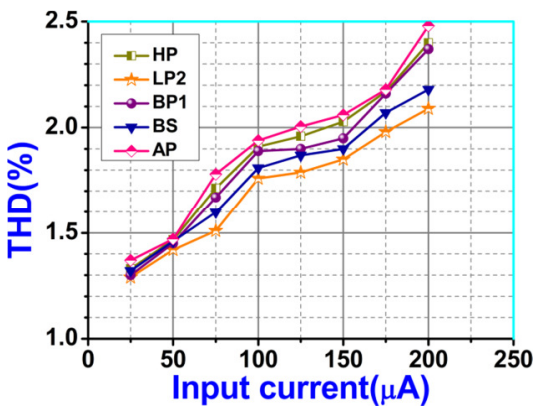

(d) For Fig. 4(b)

Fig. 12 Input amplitude versus THD curves

In order to illustrate the variations in center frequency due to the deviation in passive components used in the circuits, Monte-Carlo simulations are performed for 100 samples taking 5\% Gaussian deviations for the resistances and the capacitors. The results are presented in Fig. 13, which clearly shows that the standard deviations of center frequency for the circuits of Figs. 3(a) and 4(b) are just $178.04 \mathrm{kHz}$ and $121.79 \mathrm{kHz}$, respectively. Thus, the proposed structures show excellent sensitivity performance.

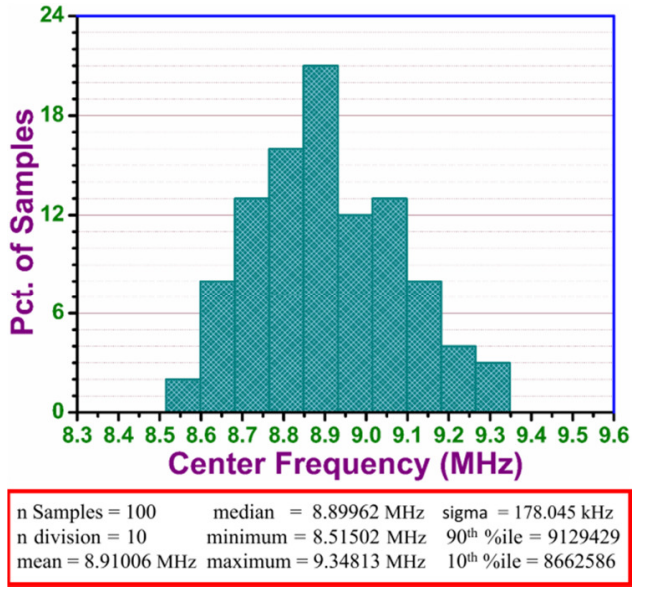

(a) For the circuit of Fig. 3(a)

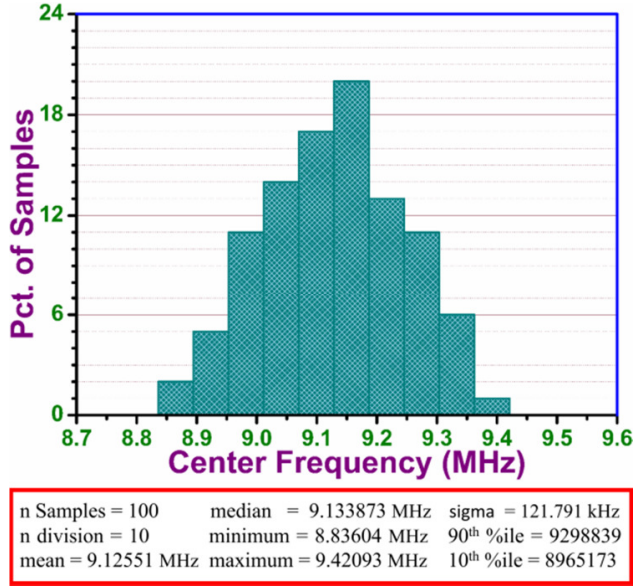

(b) For the circuit of Fig. 4(b)

Fig. 13 Monte-Carlo Simulation result of proposed BP filter

\section{Comparison with Previous Works}

The performance parameters of the designed filters are summarized and compared with other previously published related works [1, 3-18, 20-34] in Table 4. It depicts that the designed filters consume least power among all the other circuits. The comparison is done based on the following important criteria: i) the number and the name of the active block, ii) the number of 
passive elements used, iii) the mode of operation, iv) the ability to provide all five filter responses, v) use of all grounded passive elements, vi) the provision to control $\mathrm{Q}$ independent of $\omega_{0}$, vii) the electronic tenability of $\mathrm{Q}$ and $\omega_{0}$, viii) the requirement for double/negative input signals, ix) the availability of the experiment result, $\mathrm{x}$ ) the pole frequency, $\mathrm{xi}$ ) THD of BP filter, xii) the quality factor, xiii) the power consumption in $\mathrm{mW}$ unit, xiv) the supply voltage in volt unit, and $\mathrm{xv}$ ) the technology used.

It is clear from Table 4 that the circuits in [3-5, 12-16, 22-24, 26, 29-34] employ multiple active blocks. Although single active block is employed as the proposed structures in the works in [1, 6-11, 17-18, 20-21, 25, 27-28], the pole frequency (except the one in [17]) is comparatively low. Despite that, a comparatively large number of passive components is used in [18, $25,27]$. Moreover, the circuits in $[6-11,18]$ need a comparatively large power supply. In addition, not all of the basic filter responses can be provided in references [25, 27] and in parts of references [7, 20]. Furthermore, the quality factor in $[1,8,25$, 27-28] is not independently tunable with the pole frequency. Also, double/inverted input signals are required in $[6,8,9,17,20$, $21,28]$. A relatively large pole frequency with a lower power supply is offered in [17], but to achieve this one, it is necessary to pay for THD (2.5\% up to $50 \mu \mathrm{A}$ in [17]; $2.37 \%$ up to $200 \mu \mathrm{A}$ for proposed works) and power consumption. Also, the quality factor and pole frequency of this circuit are not electronically tunable. Moreover, as mentioned earlier, this circuit needs double/inverted input signals. Contrarily, the filters in $[3,6,14,21,25]$ offer better THD performances at the cost of lower pole frequency and additional power dissipation. Besides, the works in $[3,6]$ are based on BJT/ higher CMOS technology. The circuits in $[14,25]$ cannot provide the electronically tunable quality factor and pole frequency. Evidently, none of the previous works mentioned in Table 4 can simultaneously achieve the advantageous features of the filters, i.e., simple architecture, low component count, capability of delivering all the basic filter responses, least power dissipation, independent and electronic tunability, low supply voltage, higher pole frequency, low THD, and no requirement for double/inverted input signals in MISO filters.

Table 4 The comparison between the suggested and previously reported related works [1, 3-18, 20-34]

\begin{tabular}{|c|c|c|c|c|c|c|c|c|c|c|c|c|c|c|c|}
\hline $\begin{array}{l}\text { Ref. No. } \\
\text { /Year }\end{array}$ & $\mathrm{i}$ & ii & iii & iv & $\mathrm{v}$ & vi & vii & viii & Ix & $\mathrm{x}$ & $\mathrm{xi}$ & xii & xiii & xiv & $\mathrm{xv}$ \\
\hline$[1] / 2013$ & $1 \mathrm{DVCC}$ & 4 & $\mathrm{VM}$ & Yes & No & No & No & No & No & $318.13 \mathrm{kHz}$ & NR & 1 & NR & \pm 0.9 & $0.18 \mu \mathrm{m}$ \\
\hline$[3] / 2012$ & 2 VDBA & $\begin{array}{l}2 \text { (Fig. 3) } \\
3 \text { (Fig. 4) }\end{array}$ & $\mathrm{VM}$ & Yes & No & Yes & Yes & Yes & No & $1.19 \mathrm{MHz}$ & $1 \%$ & 1 & NR & \pm 1.5 & $0.35 \mu \mathrm{m}$ \\
\hline$[4] / 2020$ & 2 EXCCTA & $6+$ Switch & MX & Yes & No & Yes & Yes & No & No & $7.622 \mathrm{MHz}$ & $7.5 \%$ & 0.696 & NR & \pm 1.25 & $0.18 \mu \mathrm{m}$ \\
\hline$[5] / 2013$ & 2 CDBA & 6 & $\mathrm{VM}$ & Yes & No & Yes & No & No & No & $6.29 \mathrm{MHz}$ & NR & 1 & NR & \pm 12 & IC \\
\hline [6]/2020 & $1 \mathrm{MO}-\mathrm{CCCCTA}$ & 3 & $\mathrm{CM}$ & Yes & Yes & Yes & Yes & Yes & No & $570.164 \mathrm{kHz}$ & $0.65 \%$ & NR & NR & \pm 1.5 & $\mathrm{BJT}$ \\
\hline [7]/2011 & 1 DDCCTA & 3 & $\begin{array}{l}\mathrm{VM} \\
\mathrm{CM}\end{array}$ & $\begin{array}{l}\text { No } \\
\text { Yes }\end{array}$ & Yes & Yes & Yes & No & No & $1.59 \mathrm{MHz}$ & NR & 1 & NR & \pm 1.25 & $0.25 \mu \mathrm{m}$ \\
\hline [8]/2018 & 1 FTFN & 4 & $\mathrm{VM}$ & Yes & No & No & No & Yes & No & $1 \mathrm{MHz}$ & NR & $1 / 3$ & 6.33 & \pm 1.65 & $0.35 \mu \mathrm{m}$ \\
\hline [9]/2017 & 1 DXCCDITA & 4 & MX & Yes & No & Yes & Yes & Yes & No & $318.3 \mathrm{kHz}$ & $16 \%$ & 1 & NR & \pm 5 & $0.35 \mu \mathrm{m}$ \\
\hline$[10] / 2013$ & 1 DVCCTA & 2 & $\begin{array}{l}\mathrm{VM} \\
\mathrm{CM} \\
\end{array}$ & Yes & $\begin{array}{l}\text { No } \\
\text { Yes }\end{array}$ & Yes & Yes & No & No & $58.21 \mathrm{kHZ}$ & NR & 1 & 4.21 & \pm 1.5 & BJT \\
\hline$[11] / 2013$ & 1 CCDDCCTA & 2 & $\mathrm{CM}$ & Yes & Yes & Yes & Yes & No & No & $1.28 \mathrm{MHz}$ & $5 \%$ & 1 & NR & \pm 1.25 & $0.25 \mu \mathrm{m}$ \\
\hline$[12] / 2018$ & 6 OTA & 2 & $\mathrm{VM}$ & Yes & Yes & Yes & Yes & No & Yes & $10 \mathrm{kHz}$ & $3.4 \%$ & 0.707 & NR & \pm 15 & IC \\
\hline$[13] / 2003$ & $2 \mathrm{OTA}+1 \mathrm{CCII}$ & 2 & $\mathrm{VM}$ & Yes & No & NR & Yes & Yes & No & $15.92 \mathrm{kHz}$ & NR & 1 & NR & NR & IC \\
\hline$[14] / 2018$ & 2 FDCCII & 6 & MX & Yes & No & Yes & No & No & No & $1.59 \mathrm{MHz}$ & $0.84 \%$ & 1 & 1.32 & \pm 0.9 & $0.18 \mu \mathrm{m}$ \\
\hline$[15] / 2014$ & 2 VDTA & 2 & $\mathrm{TC}$ & No & Yes & Yes & Yes & No & No & $\approx 1 \mathrm{MHz}$ & NR & 0.5 & NR & \pm 0.9 & $0.18 \mu \mathrm{m}$ \\
\hline$[16] / 2017$ & 3 DDCC & 4 & $\mathrm{VM}$ & Yes & Yes & Yes & No & No & No & $3.18 \mathrm{MHz}$ & $6 \%$ & 1 & 2.62 & \pm 0.75 & $0.13 \mu \mathrm{m}$ \\
\hline$[17] / 2020$ & $1 \mathrm{EX}-\mathrm{CCCII}$ & 3 & MX & Yes & No & Yes & No & Yes & No & $22.9 \mathrm{MHz}$ & $2.5 \%$ & 1 & 1.35 & \pm 0.5 & $0.18 \mu \mathrm{m}$ \\
\hline$[18] / 2021$ & 1VD-EXCCII & 5 & MX & Yes & No & Yes & Yes & No & No & $8.0844 \mathrm{MHz}$ & $7.5 \%$ & 1.015 & 5.76 & \pm 1.25 & $0.18 \mu \mathrm{m}$ \\
\hline$[20] / 2015$ & $1 \mathrm{VDCC}$ & $\begin{array}{l}3 \text { (Fig. 2) } \\
4 \text { (Fig. 3) } \\
\end{array}$ & $\mathrm{VM}$ & $\begin{array}{l}\text { Yes } \\
\text { No } \\
\end{array}$ & No & Yes & Yes & Yes & Yes & $1.165 \mathrm{MHz}$ & $3 \%$ & \begin{tabular}{|l|}
1.34 \\
1.86 \\
\end{tabular} & NR & \pm 0.9 & $0.18 \mu \mathrm{m}$ \\
\hline$[21] / 2015$ & $1 \mathrm{VDCC}$ & 3 & $\mathrm{CM}$ & Yes & Yes & Yes & Yes & Yes & No & $1.2 \mathrm{MHz}$ & $0.7 \%$ & 1 & 0.87 & \pm 0.9 & $0.18 \mu \mathrm{m}$ \\
\hline$[22] / 2016$ & $2 \mathrm{VDCC}$ & 4 & $\mathrm{CM}$ & Yes & Yes & Yes & Yes & No & No & $1.59 \mathrm{MHz}$ & $6 \%$ & 1 & 1.77 & \pm 0.9 & $0.18 \mu \mathrm{m}$ \\
\hline$[23] / 2017$ & 2 VDCC & 4 & $\mathrm{CM}$ & \begin{tabular}{|l|} 
Yes \\
\end{tabular} & Yes & Yes & Yes & No & Yes & $1 \mathrm{MHz}$ & $8 \%$ & 0.5 & NR & \pm 0.9 & $0.18 \mu \mathrm{m}$ \\
\hline
\end{tabular}


Table 4 The comparison between the suggested and previously reported related works [1, 3-18, 20-34] (continued)

\begin{tabular}{|c|c|c|c|c|c|c|c|c|c|c|c|c|c|c|c|}
\hline $\begin{array}{c}\text { Ref. No. } \\
\text { /Year }\end{array}$ & $\mathrm{i}$ & ii & iii & iv & $\mathrm{v}$ & vi & vii & viii & Ix & $\mathrm{x}$ & xi & xii & xiii & xiv & $\mathrm{xv}$ \\
\hline$[24] / 2016$ & $2 \mathrm{VDCC}$ & 7 & VM & No & No & Yes & Yes & No & No & $3.02 \mathrm{MHz}$ & NR & 0.707 & NR & \pm 0.9 & $0.18 \mu \mathrm{m}$ \\
\hline$[25] / 2015$ & $1 \mathrm{VDCC}$ & 5 & VM & No & No & No & $\mathrm{No}$ & No & No & $5 \mathrm{MHz}$ & $2 \%$ & 0.707 & 0.85 & \pm 0.9 & $0.18 \mu \mathrm{m}$ \\
\hline$[26] / 2015$ & 3 VDCC & 10 & $\mathrm{VM}$ & No & No & Yes & No & No & No & $159.15 \mathrm{kHz}$ & NR & 1 & NR & \pm 0.9 & $0.18 \mu \mathrm{m}$ \\
\hline$[27] / 2018$ & $1 \mathrm{VDCC}$ & 5 & VM & No & Yes & No & Yes & No & No & $5.3 \mathrm{MHz}$ & NR & NR & 0.9 & \pm 0.9 & $0.18 \mu \mathrm{m}$ \\
\hline$[28] / 2018$ & $1 \mathrm{VDCC}$ & 3 & VM & Yes & No & No & Yes & Yes & No & $1 \mathrm{MHz}$ & $2.5 \%$ & 0.851 & 0.91 & \pm 0.9 & $0.18 \mu \mathrm{m}$ \\
\hline$[29] / 2015$ & $2 \mathrm{VDCC}$ & 9 & VM & No & No & NR & NR & NR & No & $774 \mathrm{kHz}$ & NR & NR & NR & \pm 0.9 & $0.18 \mu \mathrm{m}$ \\
\hline$[30] / 2019$ & 2 VDCC & 4 & $\mathrm{CM}$ & Yes & Yes & Yes & Yes & No & No & $1.09 \mathrm{MHz}$ & $7.2 \%$ & 1 & NR & \pm 0.9 & $0.18 \mu \mathrm{m}$ \\
\hline$[31] / 2020$ & $2 \mathrm{VDCC}$ & 4 & $\mathrm{CM}$ & Yes & Yes & Yes & Yes & No & No & $1 \mathrm{MHz}$ & $6 \%$ & 0.707 & 2.27 & \pm 0.9 & $0.18 \mu \mathrm{m}$ \\
\hline$[32] / 2019$ & $2 \mathrm{VDCC}$ & 4 & $\mathrm{CM}$ & Yes & Yes & Yes & Yes & No & No & $1.06 \mathrm{MHz}$ & $10.8 \%$ & 0.75 & 2.16 & \pm 0.9 & $0.18 \mu \mathrm{m}$ \\
\hline$[33] / 2020$ & $2 \mathrm{VDCC}$ & 3 & $\mathrm{CM}$ & Yes & Yes & Yes & Yes & No & No & $1 \mathrm{MHz}$ & NR & 1 & NR & \pm 5 & $\mathrm{IC}$ \\
\hline$[34] / 2020$ & $3 \mathrm{VDCC}$ & 5 & TC & Yes & Yes & Yes & Yes & Yes & Yes & $105.45 \mathrm{kHz}$ & $6.5 \%$ & 1 & NR & \pm 5 & IC \\
\hline $\begin{array}{l}\text { Proposed } \\
\text { filters }\end{array}$ & $1 \mathrm{VDCC}$ & $\begin{array}{l}4 \text { (Fig. 3) } \\
4 \text { (Fig. 4) }\end{array}$ & $\begin{array}{l}\text { VM } \\
\text { CM }\end{array}$ & Yes & $\begin{array}{l}\text { No } \\
\text { Yes }\end{array}$ & Yes & Yes & No & Yes & $\begin{array}{l}\text { 8.91 MHz (Figs. } \\
\text { 3(a) \& 4(a)) } \\
\text { 9.12 MHz (Figs. } \\
\text { 3(b) \& 4(b)) }\end{array}$ & $2.37 \%$ & 1 & 0.72 & \pm 0.9 & $0.18 \mu \mathrm{m}$ \\
\hline
\end{tabular}

\section{Experimental Results}

For experimental verification of the performances of the proposed structures, the VDCC block is created by using commercially available IC OPA860 from Texas Instruments as shown in Fig. 14. As recommended in datasheet [35], the resistors of $100 \Omega$ are connected in series to the bases of OTA and buffers inputs. For space convenience, only the results of the circuit of Fig. 3(a) are presented here. Although four OPA860s are needed for a single VDCC implementation, the designed filter requires only three OPA860s, as $\mathrm{W}_{\mathrm{P}}$ terminal is grounded for this particular implementation. Fig. 15(a) shows the schematic diagram of the realization of the proposed filter configuration of Fig. 3(a) using discrete components, and the actual hardware arrangement is depicted in Fig. 15(b).

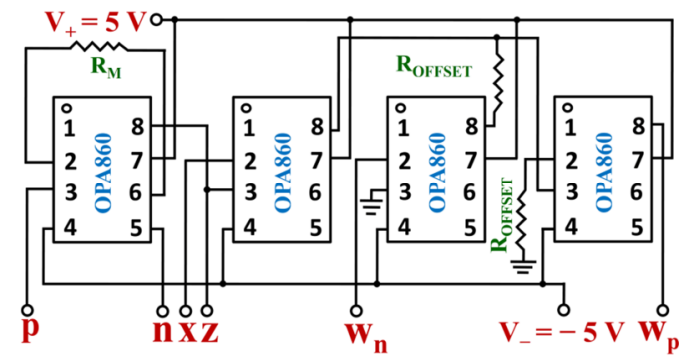

Fig. 14 VDCC using OPA860

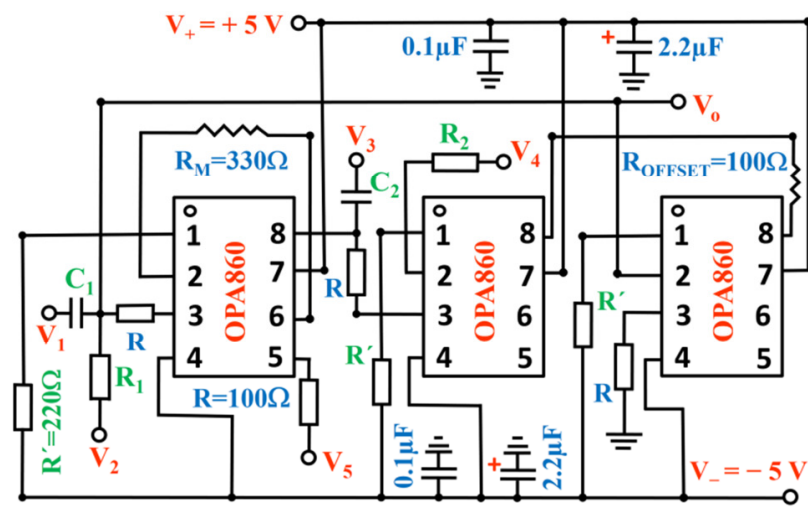

(a) Schematic diagram

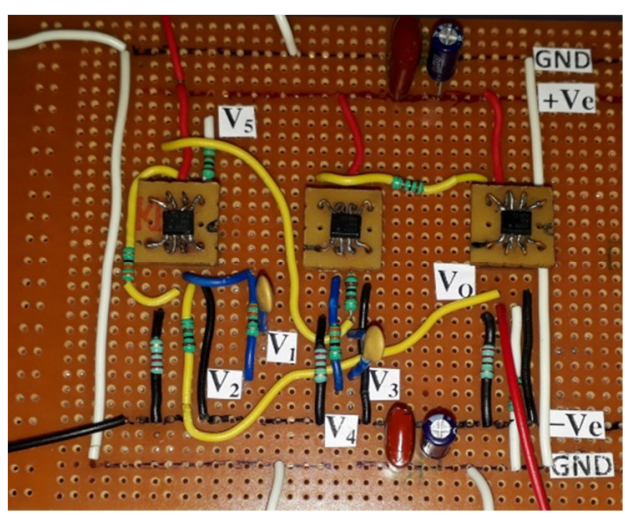

(b) experimental set up

Fig. 15 The experimental arrangement for the circuit of Fig. 3(a) by using discrete components

For hardware implementation, METRAVI Multiple power supply (RPS3002-2), RIGOL function generator (DG1022) and AGILENT Oscilloscope $(350 \mathrm{MHz}, 54641 \mathrm{~A})$ are used. The passive components selected for experimentation are $\mathrm{C}_{1}=\mathrm{C}_{2}=$ $220 \mathrm{pF}, \mathrm{R}_{1}=\mathrm{R}_{2}=330 \Omega, \mathrm{R}_{\mathrm{offset}}=100 \Omega$, and $\mathrm{R}_{\mathrm{m}}=1 / \mathrm{g}_{\mathrm{m}}=330 \Omega$. The experimental and simulation (using OPA860 IC) results 
for the HP/BP1/LP1 filter functions are depicted in Fig. 16(a), and the other BP2/LP2/BS filter functions are shown in Fig. 16(b). The simulated (using OPA860 IC) and experimental natural frequency is found to be approximately $2.14 \mathrm{MHz}$ and 2.05 $\mathrm{MHz}$ respectively. These are close to the expected values (the percentage errors are just $2.4 \%$ and $6.5 \%$ respectively). The gain and phase responses of AP function are demonstrated in Fig. 17.

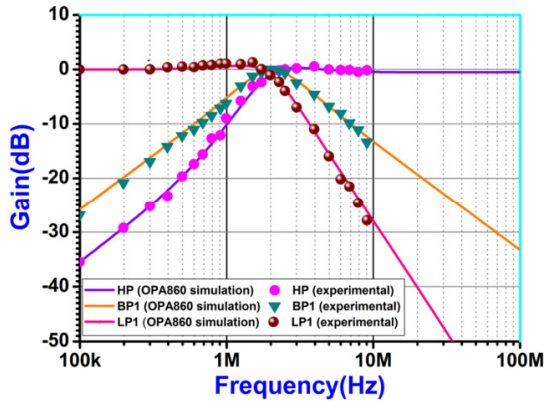

(a) HP/BP1/LP1function

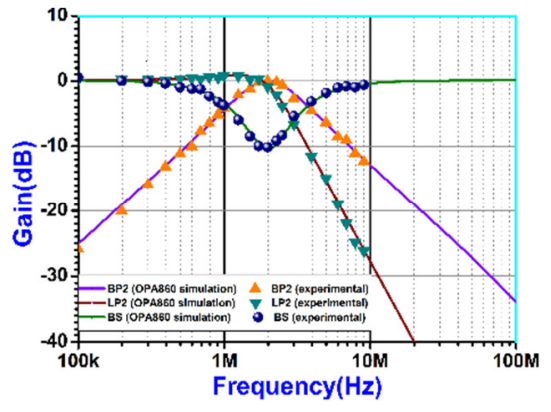

(b) BP2/LP2/BS function

Fig. 16 The simulation and experimental result for the filter of Fig. 3(a)

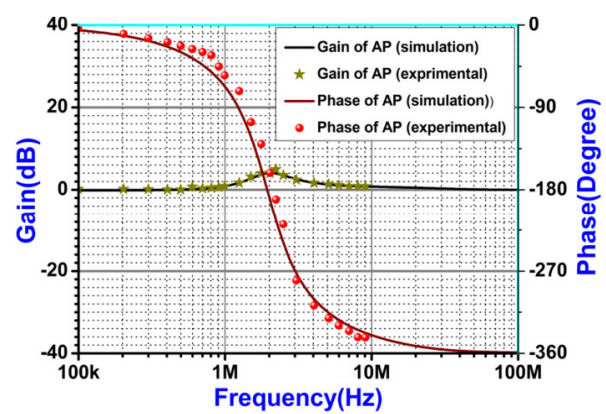

Fig. 17 The simulation and experimental result for AP filter of Fig. 3(a)

Universal filters are used in numerous applications, e.g. in FM stereo demodulators, sound systems, phase locked loop, and touch-tone telephone decoders, etc. Noise pollution can be minimized by using universal filters. Houses and offices at the noise prone places can use filters to minimize the external noise. People working in noisy areas can use particular types of earplugs fitted with filters to stop the high-frequency noises. After mixing all the outputs, universal filters are also used in guitar to operate it easily.

\section{Conclusions}

Four new (two voltage-mode MISO and two current-mode SIMO) electronically tunable universal biquad filters using VDCC and four passive components (two resistors and two capacitors) are proposed. They have very simple structures with independently tunable pole frequency and quality factor. Moreover, they can be tuned electronically without hampering bandwidth. They can realize all the five filter responses without changing the circuits' configuration. PSPICE simulator and TSMC $0.18 \mu \mathrm{m}$ CMOS parameters are used to test the workability of the proposed filters. All these circuits perform well and consume less power. The experimental results, which are based on VDCC implemented from the commercially available IC OPA860s, confirm the theoretical performances. The active and passive sensitivities are found to be low.

\section{Conflicts of Interest}

The authors declare no conflict of interest.

\section{References}

[1] J. W. Horng and Z. Y. Jhao, "Voltage-Mode Universal Biquadratic Filter Using Single DVCC," International Scholarly Research Notices, vol. 2013, pp. 1-5, March 2013. 
[2] S. Roy, T. K. Paul, and R. R. Pal, "Realization of Third-Order Voltage-Mode/Current-Mode Quadrature Oscillator Circuit Employing VDCCs and All Grounded Capacitors,” Journal of Physical Science, vol. 23, pp. 131-145, December 2018.

[3] F. Kacar, A. Yesil, and A. Noori, "New CMOS Realization of Voltage Differencing Buffered Amplifier and Its Biquad Filter Applications,” Radioengineering, vol. 21, no. 1, pp. 333-339, April 2012.

[4] M. I. A. Albrni, F. Mohammad, N. Herencsa, J. Sampe, and S. H. M. Ali, "Novel Electronically Tunable Biquadratic Mixed-Mode Universal Filter Capable of Operating in MISO and SIMO Configurations," Informacije MIDEM-Journal of Microelectronics Electronic Components and Materials, vol. 50, no. 3, pp. 189-203, July 2020.

[5] J. K. Pathak, A. K. Singh, and R. Senani, "New Voltage Mode Universal Filters Using Only Two CDBAs," International Scholarly Research Notices, vol. 2013, pp. 1-8, February 2013.

[6] S. Sirithai, S. Summart, and A. Jantakun, "Multiple-Input Single-Output Biquadratic Filter with Adjustable Amplitude," Przegląd Elektrotechniczny, vol. 96, no. 8, pp. 20-23, August 2020.

[7] N. Pandey and S. K. Paul, "Differential Difference Current Conveyor Transconductance Amplifier: A New Analog Building Block for Signal Processing," Journal of Electrical and Computer Engineering, vol. 2011, pp. 1-10, November 2011.

[8] H. Tarunkumar, A. Ranjan, and N. M. Pheiroijam, "Universal Biquadratic Filter with Minimum Number of Active FTFN," Procedia Computer Science, vol. 125, pp. 818-824, January 2018.

[9] M. Faseehuddin, J. Sampe, S. Shireen, and S. H. M. Ali, “A Novel Mix-Mode Universal Filter Employing A Single Active Element and Minimum Number of Passive Components," Informacije MIDEM-Journal of Microelectronics Electronic Components and Materials, vol. 47, no. 4, pp. 211-221, September 2017.

[10] S. Maiti and R. R. Pal, "Universal Biquadratic Filter Employing Single Differential Voltage Current Controlled Conveyor Transconductance Amplifier," Lecture Notes on Photonics and Optoelectronics, vol. 1, no. 2, pp. 56-61, December 2013.

[11] A. K. Kushwaha and S. K. Paul, "Current Mode Universal Filter Using Single Current Controlled Differential Difference Current Conveyor Transconductance Amplifier," Circuits and Systems, vol. 6, no. 10, pp. 224-236, October 2015.

[12] C. Psychalinos, C. Kasimis, and F. Khateb, "Multiple-Input Single-Output Universal Biquad Filter Using Single Output Operational Transconductance Amplifiers," AEU-International Journal of Electronics and Communications, vol. 93, pp. 360-367, September 2018.

[13] J. W. Horng, "High Input Impedance Voltage-Mode Universal Biquadratic Filter Using Two OTAs and One CCII," International Journal of Electronics, vol. 90, no. 3, pp. 185-191, June 2003.

[14] B. Chaturvedi, J. Mohan, and A. Kumar, "A New Versatile Universal Biquad Configuration for Emerging Signal Processing Applications,” Journal of Circuits, Systems and Computers, vol. 27, no. 12, 185096, February 2018.

[15] D. Prasad, M. Srivastava, and D. R. Bhaskar, "Transadmittance Type Universal Current-Mode Biquad Filter Using VDTAs,” International Scholarly Research Notices, vol. 2014, pp. 1-4, August 2014.

[16] E. Yuce, “A Single-Input Multiple-Output Voltage-Mode Second-Order Universal Filter Using Only Grounded Passive Components," Indian Journal of Engineering \& Materials Sciences, vol. 24, pp. 97-106, April 2017.

[17] D. Agarwal and S. Maheswari, "High-Performance Electronically Tunable Analog Filter Using a Single EX-CCCII," Circuits, Systems, and Signal Processing, vol. 18, no. 4 pp. 1-25, September 2020.

[18] M. Faseehuddin, N. Herencsar, N. Albrni, and J. Sampe, "Electronically Tunable Mixed-Mode Universal Filter Employing a Single Active Block and a Minimum Number of Passive Components," Applied Sciences, vol. 11, no. 1, 55, January 2021.

[19] D. Biolek, R. Senani, V. Biolkova, and Z. Kolka, “Active Elements for Analog Signal Processing; Classification, Review, and New Proposals," Radioengineering, vol. 17, no. 4, pp. 15-32, December 2008.

[20] F. Kacar, A. Yesil, and K. Gurkan, "Design and Experiment of VDDC-Based Voltage Mode Universal Filter," Indian Journal of Pure and Applied Physics, vol. 53, no. 5, pp. 341-349, May 2015.

[21] P. Lamun, P. Phatsornsiri, and U. Torteanchai, "Single VDCC-Based Current-Mode Universal Biquadratic Filter," 7th International Conference on Information Technology and Electrical Engineering (ICITEE), IEEE Press, October 2015, pp. 122-125.

[22] S. Rana, A. K. Kumawat, and P. Kumar, “A Universal Current Mode KHN Biquad Filter Using Voltage Differencing Current Conveyor," IEEE 1st International Conference on Power Electronics, Intelligent Control and Energy Systems (ICPEICES), IEEE Press, July 2016, pp. 1-5.

[23] M. Gupta and T. S. Arora, "Realization of Current Mode Universal Filter and a Dual-Mode Single Resistance Controlled Quadrature Oscillator Employing VDCC and Only Grounded Passive Elements," Advances in Electrical and Electronic Engineering, vol. 15, no. 5, pp. 833-845, December 2017. 
[24] R. Jain and P. Kumar, "VDCC Based Voltage Mode Tow-Thomas Biquad Filter," IEEE $1^{\text {st }}$ International Conference on Power Electronics, Intelligent Control and Energy Systems (ICPEICES), IEEE Press, July 2016, pp. 1-4.

[25] R. Jain, "Single Voltage Differencing Current Conveyor Based Second-Order Filter Realization," International Journal of Advanced Research in Electronics and Communication Engineering (IJARECE), vol. 4, no. 5, pp. 1218-1224, May 2015.

[26] M. Rawat and M. Bansal, "A Voltage Mode Biquad with Lowpass, Bandpass and Notch Outputs Using Voltage Differencing Current Conveyor," International Journal of Advanced Research in Computer and Communication Engineering, vol. 4, no. 5, pp. 506-508, May 2015.

[27] S. Mishra and P. Kumar, "Biquad Filter Design Using VDCC (Earth Resistor Help in Designing of Biquad Filter Using VDCC),” International Journal of Research, vol. 5, no. 15, pp. 1979-1985, May 2018.

[28] P. Uttaphut, "Single VDCC-Based Electronically Tunable Voltage-Mode Second Order Universal Filter," Przegląd Elektrotechniczny, vol. 94, no. 4, pp. 22-25, April 2018.

[29] D. Prasad, A. Ahmad, A. Shukla, A. Mukhopadhyay, B. B. Sharma, and M. Srivastava, "Novel VDCC Based Low-Pass and High-Pass Ladder Filters," Annual IEEE India Conference (INDICON), IEEE Press, December 2015, pp. 1-3.

[30] T. S. Arora, B. Rohil, and S. Gupta, "Fully Integrable/Cascadable CM Universal Filter And CM Quadrature Oscillator Using VDCC and Only Grounded Passive Elements,” Journal of Circuits, Systems and Computers, vol. 28, no. 11, 1950181, October 2019.

[31] M. Gupta and T. S. Arora, "Various Applications of Analog Signal Processing Employing Voltage Differencing Current Conveyor and Only Grounded Passive Elements: A Re-Convertible Approach,” SN Applied Sciences, vol. 2, no. 9, pp. 1-18, September 2020.

[32] M. Gupta, P. Dogra, and T. S. Arora, "Novel Current Mode Universal Filter and Dual-Mode Quadrature Oscillator Using VDCC and All Grounded Passive Elements," Australian Journal of Electrical and Electronics Engineering, vol. 16, no. 4, pp. 220-236, July 2019.

[33] T. S. Arora, "Realization of Current-Mode Universal Filter Utilising Minimum Active Elements and Only Grounded Passive Components," 7th International Conference on Signal Processing and Integrated Networks (SPIN), IEEE Press, February 2020, pp. 681-686.

[34] Siripruchyanun and W. Jaikla, "A Transconductance-Mode Multifunction Filter with High Input and High Output Impedance Nodes Using Voltage Differencing Current Conveyors (VDCCs)," Advances in Electrical and Electronic Engineering, vol. 18, no. 4, pp. 242-254, December 2020.

[35] “OPA860-Wide Bandwidth Operational Transconductance Amplifier (OTA) and Buffer,” http://www.ti.com/lit/ ds/sbos331c/sbos331c.pdf, August 31, 2008.

Copyright $(\mathrm{C}$ by the authors. Licensee TAETI, Taiwan. This article is an open access article distributed under the terms and conditions of the Creative Commons Attribution (CC BY-NC) license (https://creativecommons.org/licenses/by-nc/4.0/). 